\title{
Interactive comment on "Onset and propagation of drought into soil moisture and vegetation responses during the 2012-2019 drought in Southern California" by Maria Magdalena Warter et
} al.

\section{Anonymous Referee \#2}

Received and published: 9 February 2021

This paper discusses the impacts of prolonged recent drought in California on the vegetation and soil moisture dynamics of natural grasslands in two contrasting climatic regions of Santa Barbara Co, CA. This controlled and localized experiment leads to some interesting findings re. grassland response to drought, with ramifications for wildfire and species diversity under varying climate change scenarios. ifications and potential changes in definition of drought vs. non-drought years are required. In addition, a few suggestions to enhance readability are given below. 


\section{General comments:}

Not sure the title makes complete sense as written. Taken in parts. . Onset of drought into soil moisture responses? Consider reworking, with a focus on natural grasslands.

In general, I would recommend reducing use of "we" and shifting to a more passive tone throughout the manuscript. Shifts the emphasis from what the authors did and thought to a more objective viewpoint.

Parts are overly wordy and could use some critical editing to pare down to what is really essential to move the key story forward. The first paragraph of the introduction, for example, discusses forest response to drought in depth before getting to grasslands, which is the focus of the paper. Revisit the wording of the first sentence - could read something like "resulting in substantial impacts to water resources and ecosystems. These impacts varied regionally, depending on climate, elevation and biome... For example, upland forests...[1 or 2 sentences]. The impacts of drought on California's grasslands have been less well studied..."

Specific comments:

L158: Add citation for the Penman-Monteith equation.

L165: Explain the choice of the shallowest soil moisture observations as reference in this study. Why not the 20 or $50 \mathrm{~cm}$ measurements, which may be more representative of the root zone?

Fig. 2: Can the time markers in this figure be at 1-1-YYYY rather than 1-4-YYYY (is that April 1)? Seems a little cleaner. . and less ambiguous re. date format. Inclusion of 2008 and 2009 in the non-drought period is problematic, since most of SB County was under moderate-severe drought in those years. Why not separate out truly non-drought years, defined as years with some prescribed fraction in drought-free conditions, even if they are not temporally contiguous?

Printer-friendly version

Sec 2.4: Discuss noise reduction and normalization applied to the NDVI data obtained

Discussion paper 
from Landsats 5, 7 and 8 to generate multi-year timeseries. Were TOA band values used, or surface reflectance?

Sec 2.5.1: The description of the Soil Moisture Balance Model could be shortened significantly.

L215: ". . . to estimate potential evapotranspiration (PET)..."

Table 1 caption: Remove first of two "used" in first sentence.

L253: This sentence does not read well. Is there a missing comma after NDVI?

Sec 2.5.4: Seems to be an inconsistency in stated calibration range between line 267 (2008-2019) and L 272 (2008-2014). Please clarify.

L339: It is surprising that there is no difference in precipitation between drought and non-drought years. Perhaps a more stringent separation of these years would yield greater difference?

L366: What is meant by "aggressive strategy"? Maybe a use a different term.

L 451-452: The difference in response isn't only due to soil texture, right? Difference in climate (aridity) also drove response.

Interactive comment on Hydrol. Earth Syst. Sci. Discuss., https://doi.org/10.5194/hess-2020479, 2020. 